\title{
Plantão psicológico no Brasil (1997-2009): saberes e práticas compartilhados
}

\section{Emergency psychological services in Brazil (1997-2009): shared knowledge and practices}

\author{
Bianca Nascimento de SOUZA \\ Airle Miranda de SOUZA
}

\section{Resumo}

O objetivo deste trabalho foi investigar a produção científica sobre Plantão Psicológico no Brasil, entre 1997 e 2009, através de pesquisa em bases eletrônicas de dados científicos, utilizando o descritor "plantão psicológico". Obtiveram-se 38 resumos, analisados a partir das seguintes categorias: distribuição, autoria, filiação institucional, fonte, ano, suporte de publicação, população alvo, enfoque teórico, natureza do trabalho e região geográfica do país. Os resultados sugerem que as bases eletrônicas de dados constituem atualmente importante fonte de acesso à produção brasileira sobre Plantão Psicológico. Verifica-se uma prevalência na produção sobre o assunto na Região Sudeste, assim como na utilização da Abordagem Centrada na Pessoa, revelando maior ênfase em pesquisa relacionada à dissertação, com predominância de produção em 2005 e 2006.

Unitermos: Bases de dados. Plantão psicológico. Produção científica.

\begin{abstract}
The purpose of this study was to investigate scientific production on Emergency Psychological Services in Brazil between 1997 and 2009 by trawling scientific, electronic databases, using the descriptor Emergency Psychological Services. Thirty-eight abstracts were obtained, analyzed based on the following categories: distribution, authorship, institutional affiliation, source, year, publication support, target population, theoretical approach, nature of work and geographic region of the country. The results suggest that the electronic databases are currently an important source of access to production on Emergency Psychological Services in Brazil. It is in the southeast where we see a prevalence in production on this subject, as well as the use of the Person-Centered Approach, revealing a greater emphasis on research related to dissertations, with the greatest level of production being noted in 2005 and 2006.
\end{abstract}

Uniterms: Databases. Psychological emergency attendance. Scientific production.

Embora exista produção científica sobre Plantão

Psicológico, raras são as pesquisas de revisão sistemática que oferecem uma visão de conjunto acerca dessa área de conhecimento. Especialmente na última década do século XXI, são escassos os trabalhos publicados que apresentam um quadro geral da evolução desse proce-

$\boldsymbol{\nabla \nabla \nabla \nabla}$

1 Universidade Federal do Pará, Programa de Pós-Graduação em Psicologia. R. Augusto Corrêa, 1, Guamá, 66075-110, Belém, PA, Brasil. Correspondência para/Correspondence to: B.N. SOUZA. E-mail: <bianasso@hotmail.com>.

2 Universidade Federal do Pará, Faculdade de Psicologia, Laboratório de Estudos do Luto e Saúde. Belém, PA, Brasil.

Agradecimento: Ao Conselho Nacional de Desenvolvimento Científico e Tecnológico pela bolsa de estudo que possibilitou a realização deste trabalho. 
dimento. Diante de tal realidade, julgou-se oportuno proceder a um levantamento sobre Plantão Psicológico no Brasil, no período de 1997 a 2009, procurando delinear tendências atuais e perspectivas científicas da área.

A escolha do tema justifica-se pela relevância que uma visão de conjunto das características da produção científica nacional sobre Plantão Psicológico pode ter para o desenvolvimento dessa modalidade no país. Por outro lado, a abrangência deste trabalho, rastreando pesquisas feitas em todo o território nacional, possibilita visualizar a produção científica nas diversas regiões do país, bem como apontar distinções de natureza econômica e educacional, o que influi na qualidade, viabilidade e quantidade de pesquisa acerca do Plantão Psicológico.

A escolha do período de doze anos justifica-se pelo fato de que no Brasil, apesar de o Plantão Psicológico ter surgido oficialmente em 1969 (Tassinari, 1999), somente no final da década de 1980, segundo Rosemberg (1987), foi que brotou a primeira sistematização pública, pois inicialmente era entendido como uma proposta alternativa.

Nesse sentido, a produção científica no Brasil sobre Plantão Psicológico é relativamente recente e não se esperava encontrar, portanto, uma produção muito extensa num levantamento sistemático.

Um levantamento bibliográfico referente a todas as regiões do país e a período longo precisava de limites que possibilitassem o acesso às informações desejadas. Destarte, necessitava-se garantir critérios para comparar as categorias investigadas. Portanto, a utilização das bases de dados nacionais tornou-se o meio mais viável, haja vista que os trabalhos por elas aceitos passam por rígida avaliação de critérios científicos, possuindo, consequentemente, padrões científicos desejados.

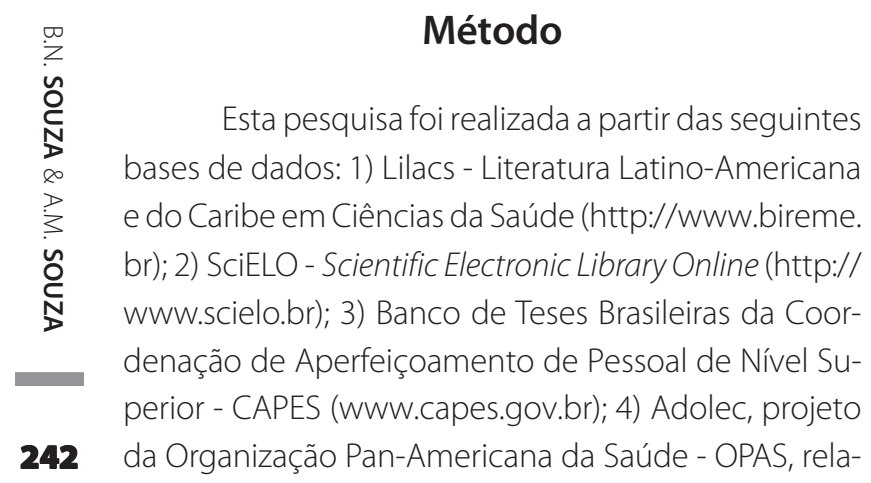

tivo à adolescência, coordenado pelo Programa de Saúde Materno-Infantil (http://www.adolec.br); 5) PAHO - Pan American Health Organization (http:// bireme.br/iahlil/homepage); 6) WHOLIS - Sistema de Informação da Biblioteca da Organização Mundial de Saúde (http://www.bireme.br/iahlil/homepage.htm); 7) Indexpsi Periódicos Técnicos Científicos (http://www. bvs-psi.org.br); 8) Indexpsi teses (http://www.bvs-psi. org.br); 9) PEPsic - Periódicos Eletrônicos em Psicologia (www.scielo.bvs-psi.org.br); 10) Banco de Teses da Universidade de São Paulo - USP (http://www.teses.usp.br); e 11) Sistema de Publicações Eletrônicas de Teses e Dissertações da Pontifícia Universidade Católica - PUC-Campinas (http://www.puc-campinas.edu.br/pos/teses_ dissertacoes.aspx?id=1).

Os trabalhos foram analisados no que se refere às categorias 8 (Enfoque Teórico) e 9 (Natureza do Trabalho), a partir do julgamento dos resumos dos artigos.

Para pesquisar os resumos em português nas bases de dados, foi utilizada a expressão "plantão psicológico". A combinação entre as duas palavras foi usada considerando que os artigos buscados estariam contidos em tal classificação.

Encontrado o material, procedeu-se à leitura dos resumos para selecionar as publicações que interessavam à pesquisa, a partir dos requisitos previamente estabelecidos, bem como para verificar os artigos presentes em mais de uma base de dados.

Em seguida, as informações foram organizadas, considerando-se as seguintes categorias, de acordo com Ferreira e Yoshida (2004): (1) distribuição de frequência; (2) autoria (única, dupla ou múltipla, para mais de dois autores); (3) filiação institucional dos autores; (4) fonte de publicação; (5) ano da produção; (6) suporte da produção (artigo, capítulo de livro, livro, dissertação de mestrado, tese de doutorado); (7) população alvo (crianças, adolescentes, adultos, alunos, profissionais e misto; (8) enfoque teórico; (9) natureza do trabalho (relato de experiência, trabalho teórico ou de pesquisa) e (10) região geográfica do país.

\section{Resultados e Discussão}

A pesquisa, realizada nas bases de dados Lilacs, Adolec, SciELO, Banco de Tese Brasileiras da CAPES, PAHO, 
WHOLIS, Indexpsi Periódicos Técnicos Científicos, Indexpsi teses, PEPsic, Banco de Teses da USP e Sistema de Publicações Eletrônicas de Teses e Dissertações da PUC-Campinas, obteve o total de 81 artigos. Dentre eles, 17 não tiveram relevância para esta pesquisa, por não estarem relacionados com as práticas em Plantão Psicológico, porém apareceram no resultado devido ao fato de possuírem em seus resumos as palavras "plantão" e "psicológico". Foram ainda desprezados 26 trabalhos, por serem repetidos, assim totalizando uma amostra de 38 artigos.

A partir da discriminação dos trabalhos, foram encontrados os seguintes índices: a base Lilacs apresentou 11 (68,75\%) artigos dentre as 16 referências à expressão "plantão psicológico"; SciELO, com 3 artigos, apresentando 75,00\% de referência; o Banco de Teses Brasileiras da CAPES, com 32 trabalhos, sendo que 21 $(65,62 \%)$ mencionavam a modalidade de atendimento em questão; a Indexpsi Teses, com 8 trabalhos, todos (100,00\%) sobre Plantão Psicológico; a Adolec, com 2 referências encontradas e porcentagem de 100,00\%; 0 Indexpsi Periódicos Técnicos Científicos, com 8 trabalhos (100,00\%), o Banco de Teses da USP e o Sistema de Publicações Eletrônicas de Teses e Dissertações da PUC-Campinas, com 4 trabalhos cada um; o PEPsic - Periódicos Eletrônicos em Psicologia, com 11 trabalhos. Excluindo-se as referências repetidas, foram encontradas 38 referências a Plantão Psicológico, representando 46,91\% do total de trabalhos encontrados.

O Banco de Teses Brasileiras da CAPES reúne um acervo considerável de teses e dissertações sobre Plantão Psicológico, respondendo por 78,94\% dos trabalhos encontrados nas diferentes bases de dados. Esse índice elevado se justifica pelo fato de as teses e dissertações constituírem a maior parte da produção científica encontrada na pesquisa. Os autores desses trabalhos são: Almeida (2005), Araújo (2002), Aun (2005), Braga (2005), Camargo (2002), Chalom (2001), Cipriano (2005), Fernandes (2005), Ferreira (2006), Furigo (2006), Guedes (2006), Melo (2004), Messias (2002), Moreira (2002), Mosqueira (2008), Mozena (2009), Oliveira (2005), Oliveira (2006), Paparelli (2005), Perches (2009), Pereira (1999), Rocha (2006), Schmidt (2004), Tassinari (1999; 2003), Vendruscolo (2006), Yehia (2004), Zanoni (2008).

Todavia, a maior proporção de trabalhos indexados não corresponde necessariamente a maior produ- ção na área, pois nem todos os editores submetem a indexação os trabalhos recebidos, seja porque foram indeferidos por critério da base de dados, seja porque não houve possibilidade ou iniciativa dos autores para fazê-lo.

Deve-se considerar que uma quantidade maior de trabalhos aceitos e divulgados nas bases de dados proporciona maior visibilidade da produção científica a respeito de determinado assunto. Assim, viabiliza repercussões sobre a área de conhecimento em questão, bem como a articulação das instituições de ensino e seus pares enquanto produtores de conhecimento científico, no sentido de se manterem atualizados sobre o que se produz no âmbito nacional e de refletirem sobre suas práticas, possibilitando novas construções.

No que toca à categoria Autoria, dos 38 trabalhos obtidos, 30 eram de autoria única, equivalendo a um percentual de 78,94\%, e representando um valor superior a três quartos dos trabalhos acessados. Para autoria dupla e múltipla, encontrou-se índice de 10,52\% em cada uma das modalidades.

No item Filiação Institucional, em um total de 38 referências acessadas, $16(42,10 \%)$ eram vinculadas à Universidade de São Paulo (USP), 10 (26,31\%) à Pontifícia Universidade Católica de Campinas (PUC-Campinas), 2 $(5,26 \%)$ à Universidade Federal do Rio de Janeiro (UFRJ), 1 (2,63\%) à Pontifícia Universidade Católica de São Paulo (PUC-SP), 1 (2,63\%) pertencia à Universidade Católica de Pernambuco (UNICAP) enquanto $8(21,05 \%)$ não apresentaram, nos resumos, informações sobre a filiação institucional (Tabela 1). Essa omissão não só dificulta a identificação da procedência dos trabalhos, como também impede a vinculação do nome do autor a uma instituição ou grupo de pesquisa.

Com relação à Distribuição Geográfica das instituições referidas, a maioria delas está localizada na Região Sudeste, destacando-se o Estado de São Paulo como maior detentor das publicações obtidas nas bases de dados, com $71,05 \%$ do total de trabalhos encontrados. Em segundo lugar ficou o estado do Rio de Janeiro, com a porcentagem de 5,26\% e por último o estado de Pernambuco, com o total de 2,64\% das publicações. Contudo, esse índice há que ser visto com cautela, pois a pesquisa revelou um percentual considerável de 21,05\% de trabalhos sem informação a respeito da filiação institucional dos autores. 
No mesmo sentido dos dados obtidos, O.H. Yamamoto, Souza e M.E. Yamamoto (1999) e Yamamoto et al. (2002) realizaram pesquisa sobre a produção da Psicologia nos periódicos brasileiros e constataram que a maior parte dos artigos das publicações investigadas teve origem na Região Sudeste do Brasil (Tabela 1).

Quanto ao item Fonte de Publicação, os dados obtidos não permitiram identificar os periódicos em que os artigos foram publicados, haja vista que somente 13 trabalhos (34,21\%) continham essa referência. Entre as fontes de publicação citadas estão: Imaginário (USP), Psicólogo inFormação (Universidade Metodista de São Paulo - UMESP), Boletim de Psicologia (Sociedade de Psicologia de São Paulo), Estudo de Psicologia (PUC-Campinas), Psicologia: reflexão e crítica (Universidade Federal do Rio Grande do Sul), Psicologia: ciência e profissão (Conselho Federal e Conselhos Regionais de Psicologia), Caderno de Psicologia (Universidade Federal de Minas Gerais) e Psikhê (Curso de Psicologia do Centro Universitário FMU) (Tabela 2).

Em relação à produção anual no Brasil, os anos de 2005 e 2006 se destacam com o número de 7 produções cada um, seguidos dos anos de 2002, 2004 e 2008, com 4 trabalhos cada um. Já, dentre os anos de menor produção, estão 1999, 2001, 2003, 2007 e 2009, com 2 referências anuais, além de 1997, com somente 1 referência. Portanto, a média de trabalhos sobre Plantão Psicológico no país foi de 3,16/ano, observando-se decréscimo a partir de 2007.

Todavia, há que se questionar o fato de, em 1997, somente uma produção ter sido indexada nas bases de dados. Quanto à existência de apenas 2 produções nos anos de 1999,2001,2003,2007,2008 e 2009, tem-se como hipótese explicativa a possível diminuição no contingente de mestrandos e doutorandos concluintes, o que também explicaria a ausência de produção nos anos de 1998 e 2000 (Tabela 3).

Tabela 1. Filiação institucional e região.

\begin{tabular}{lccc}
\hline Instituição & Frequência & $\%$ & Região \\
\hline Universidade de São Paulo - USP & 16 & 42,10 & Sudeste \\
Pontifícia Universidade Católica de São Paulo - PUC-SP & 1 & 2,63 & Sudeste \\
Pontifícia Universidade Católica de Campinas - PUC-Campinas & 10 & 26,31 & Sudeste \\
Universidade Federal do Rio de Janeiro - UFRJ & 2 & 5,26 & Sudeste \\
Universidade Católica de Pernambuco & 1 & 2,63 & Nordeste \\
Sem Filiação Institucional & 8 & 21,05 & - \\
\hline Total & 38 & 100,00 & \\
\hline
\end{tabular}

Fonte: Lilacs, Adolec, SciELO, Banco de Tese Brasileiras da CAPES, PAHO, WHOLIS, Indexpsi Periódicos Técnicos Científicos; Indexpsi teses e PEPsic - Periódicos Eletrônicos em Psicologia. Acessados em agosto de 2009.

Tabela 2. Distribuição das referências segundo o periódico e a instituição editora no Brasil.

\begin{tabular}{|c|c|c|c|c|}
\hline & Título do Periódico & Instituição/Editora & Frequência & $\%$ \\
\hline \multirow{10}{*}{ 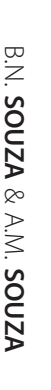 } & Revista Imaginário & Universidade de São Paulo - USP & 2 & 5,26 \\
\hline & Revista Psicólogo inFormação & Universidade Metodista de São Paulo - UMESP & 1 & 2,63 \\
\hline & Revista Boletim de Psicologia & Sociedade de Psicologia de São Paulo & 3 & 7,89 \\
\hline & Revista Estudo de Psicologia & Pontifícia Universidade Católica - PUC-Campinas & 2 & 5,26 \\
\hline & Revista Psicologia: reflexão e crítica & Universidade Federal do Rio Grande do Sul & 1 & 2,63 \\
\hline & Revista Psicologia: ciência e profissão & Conselho Federal e Conselhos Regionais de Psicologia & 2 & 5,26 \\
\hline & Revista Psikhê & Curso de Psicologia do Centro Universitário FMU & 1 & 2,63 \\
\hline & Revista Caderno de Psicologia & Universidade Federal de Minas Gerais & 1 & 2,63 \\
\hline & Sem Referência & - & 25 & 66,00 \\
\hline & Total & & 38 & 100,00 \\
\hline
\end{tabular}

Fonte: Lilacs, Adolec, SciELO, Banco de Tese Brasileiras da CAPES, PAHO, WHOLIS, Indexpsi Periódicos Técnicos Científicos; Indexpsi teses e PEPsic - Periódicos 
Tabela 3. Produção anual no Brasil sobre Plantão Psicológico (1997-2009)

\begin{tabular}{lcc}
\hline Ano & Frequência & $\%$ \\
\hline 1997 & 1 & 2,63 \\
1998 & 0 & 0,00 \\
1999 & 2 & 5,26 \\
2000 & 0 & 0,00 \\
2001 & 2 & 5,26 \\
2002 & 5 & 13,15 \\
2003 & 2 & 5,26 \\
2004 & 4 & 10,52 \\
2005 & 7 & 18,42 \\
2006 & 7 & 18,42 \\
2007 & 2 & 5,26 \\
2008 & 4 & 10,52 \\
2009 & 2 & 5,26 \\
\hline Total & 36 & 100,00 \\
\hline
\end{tabular}

Fonte: Lilacs, Adolec, SciELO, Banco de Tese Brasileiras da CAPES, PAHO, WHOLIS, Indexpsi Periódicos Técnicos Científicos; Indexpsi teses e PEPsic-Periódicos Eletrônicos em Psicologia. Acessados em agosto de 2009 .

No que se refere aos tipos de suporte das publicações brasileiras, 11 trabalhos (28,94\%) eram artigos, 19 (50\%) dissertações e 8 (21,05\%) teses.

Em relação às teses e dissertações, apesar de submetidas à avaliação em banca, a publicação fica restrita a poucos exemplares, dificultando a divulgação do material. Porém, essa realidade está se modificando em função da Internet, que promove um acesso mais fácil aos trabalhos, disponibilizados em sites científicos ou das instituições a que os autores são filiados.

Relativamente à população alvo dos trabalhos obtidos nesta pesquisa, a categoria de adultos foi a que apresentou maior número, com 7 (18,42\%) trabalhos, seguida pelos profissionais e estudantes, com resultado de 6 (15,78\%) trabalhos cada uma, enquanto a população adolescente e mista (crianças, adolescentes, adultos e idosos) obteve a quantidade de 4 (10,52\%) trabalhos. Os trabalhos com a população alvo de crianças foram os que obtiveram menor porcentagem, com apenas 5,26\%. Por outro lado, em 21,05\% dos trabalhos não foi possível identificar a população alvo, tanto pela falta de informação no resumo, quanto por serem, em sua maioria, trabalhos teóricos, que não contemplam um tipo específico de população, mas que se destinam à discussão de princípios gerais do Plantão Psicológico.
Em relação ao Enfoque Teórico, verificou-se que a dominância é da Abordagem Centrada na Pessoa (ACP), com um índice de 94,74\%. Já 2,63\% dos materiais obtidos abordavam o Plantão Psicológico a partir da orientação Psicodinâmica e da ACP, enquanto outros 2,63\% dos trabalhos tratavam do assunto sob a perspectiva da Abordagem Comportamental e da ACP. Acredita-se que os trabalhos de enfoque teórico misto sinalizem um princípio de pesquisas no sentido de estabelecer diálogo entre a Abordagem Centrada na Pessoa (que fundamenta teoricamente o Plantão Psicológico) e outras abordagens, no caso a Psicodinâmica e Comportamental, tentando, assim, preencher lacunas da prática do Plantão.

Na análise das referências quanto à Natureza dos trabalhos, observou-se maior incidência de trabalhos de pesquisa (92,11\%), seguidos de relato de experiência (2,63\%), implantação do Plantão Psicológico (2,63\%) e projeto de extensão (2,63\%).

Deve-se considerar ainda que o Plantão Psicológico foi reconhecido pelo Conselho Federal de Psicologia, que, em documento oficial, classificou-o como alternativa de atenção psicológica em relação à psicoterapia tradicional, percebendo-o como iniciativa inovadora e capaz de romper parâmetros (Mahfoud, 1999).

No Plantão Psicológico, lida-se com a queixa enquanto sintoma de uma demanda. Por vezes, quando o cliente procura ajuda profissional para sua urgência, chega com uma queixa e ao longo do atendimento revela-a distinta da sua real questão urgente. Nesse sentido, o Plantão pode ter a função de iniciar um processo de reorganização do self, esclarecendo uma problemática, constituindo-se como espaço de expressão e acolhimento de angústia, sendo sobretudo "um processo com começo, meio e fim" (Chalom et al., 1999, p.180).

Ter um atendimento psicológico disponível, no momento em que ocorre uma demanda emocional urgente, diminui a ansiedade e angústia, possibilitando o surgimento de recursos inerentes à pessoa para que ela busque soluções para seu impasse. Outra evidência é que o Plantão gera economia para o sistema institucional que o disponibiliza, promovendo encaminhamentos internos e externos bem melhor direcionados, pois são decididos conjuntamente entre plantonista e cliente (Cury, 1999). 
As ações do plantonista são pautadas nas atitudes facilitadoras, sendo suas intervenções dependentes da necessidade e motivação interna da pessoa atendida, cujas demandas variam em complexidade, podendo ir desde a necessidade de esclarecimento de dúvida sobre assuntos simples, até assuntos técnicos.

Plantonista e cliente, conjuntamente, buscam na vivência imediata deste, suas potencialidades que precisem ser desveladas. A escuta e o interesse do plantonista em ajudar o cliente desempenham função primordial. Ao ser acolhida por intermédio das atitudes facilitadoras do plantonista, a partir da relação intersubjetiva estabelecida com este, a pessoa experiencia um ambiente de segurança que facilita a abertura a novas possibilidades de compreensão de si, e começa então a integrar elementos que estavam fragmentados em seu ser, iniciando um processo de mudança.

Palmieri (2005), em pesquisa de mestrado, disponibilizou o Plantão Psicológico em hospital geral de uma cidade do interior do Estado de São Paulo, com o objetivo de compreender os desafios e potencialidades desse serviço para os profissionais do hospital. Os participantes compreenderam o Plantão Psicológico em sua função de oferecer-Ihes segurança e um clima de sigilo no ambiente profissional.

Kovács, Kobayashi, Santos e Avancini (2001) desenvolveram o Plantão Psicológico em uma Unidade de Cuidados Paliativos. O público atendido abrangeu pessoas com câncer avançado e seus familiares. Os temas levantados pelos participantes hospitalizados foram a dor, na dimensão física, psíquica, social e espiritual, assim como os distúrbios na comunicação. Já para os familiares emergiu a tristeza pela perda, assim como distúrbios na comunicação. A oferta do serviço no referido ambiente facilitou o esclarecimento de necessidades, a expressão de sentimentos e a comunicação das pessoas atendidas.

Moreira (2002) também disponibilizou o Plantão Psicológico, atendendo clientes egressos da primeira internação psiquiátrica. Os participantes revelaram sentimento de solidão, inutilidade, tristeza, carência de relacionamento afetivo gratificante (funcionamento depressivo) e evidenciaram fragilidade diante das circunstâncias da vida (funcionamento paranoico), além de insatisfação sobre o desconhecimento de si e de suas potencialidades. Os resultados obtidos apontaram a necessidade imediata de um programa de saúde que atendesse à demanda vivenciada subjetivamente pelos participantes, pois o tratamento ambulatorial priorizou a terapêutica medicamentosa. O setting terapêutico acolhedor, permeado de afetividade e de atitudes de empatia e aceitação positiva incondicional, facilitou o diálogo, propiciando a escuta das vivências emocionais dos clientes, no exato momento em que buscaram solução para suas dificuldades, revelando-se como uma possibilidade de resgate da autonomia e da saúde dos mesmos.

Vendruscolo (2006) ofertou o Plantão Psicológico e desenvolveu sua investigação a partir de um estudo de caso. $O$ atendimento no Plantão foi solicitado pela mãe de uma adolescente, e logo em seguida disponibilizado à jovem, que havia finalizado seu tratamento oncológico. A queixa inicial era de ansiedade e medo de dormir. No decorrer das sessões, a cliente revelou sua demanda sobre o medo de adoecer (notívago) novamente, assim como sentimento de religiosidade. $O$ atendimento psicológico configurou-se como um acolhimento existencial e possibilitou a expressão e elaboração de sentimentos e ideias que afligiam a cliente, além de auxiliá-la na construção de um sentido para sua vivência atual.

Contudo, responder à diversidade e singularidade das demandas de ajuda psicológica que se apresentam no Plantão apenas é possível com o apoio de políticas mais amplas do que o serviço pode ofertar em uma instituição (Schmidt, 2004). O Plantão Psicológico pode ser instituído em diversos locais ou organizações, como escolas, clínicas-escola de cursos de Psicologia, hospitais, instituiç̧ões da área jurídica e esportiva, clínicas psicológicas privadas, entre outros espaços abertos à comunidade.

Sobre a eficiência dessa modalidade de assistência, Talmom (1990) concluiu, em uma pesquisa com 200 participantes, que $78 \%$ deles abandonaram a psicoterapia não por desistência; simplesmente não voltaram porque se sentiram satisfeitos com os resultados da(s) primeira(s) sessão(s). Esses dados sugerem que uma quantidade pequena de encontros com o plantonista, ou um único encontro, tem função terapêutica e pode ser suficiente para a pessoa atendida iniciar um processo de organização interna e prosseguir sem ajuda psicológica. 
O que levaria as pessoas, em um período curto como oferece o Plantão, a apresentar mudanças após o atendimento? Em sua tese, Perches (2009) apontou a ocorrência de mudança psicológica em pessoas atendidas no Plantão, entendendo tal mudança como a atribuição de significado às experiências, ou de sentido às angústias, a partir de um processo de simbolização das vivências no presente imediato. Concluiu que os elementos que facilitam esse processo são: a procura espontânea do cliente pelo Plantão Psicológico, motivada pela experiência da angústia; o tempo como uma possibilidade de atualização da historicidade, por meio das peculiaridades do encontro intersubjetivo no Plantão; o estar na relação, evidenciando a importância da reciprocidade e da mutualidade na relação, uma vez que a simbolização adequada ocorre a partir da fala e da escuta genuína de ambos, plantonista e cliente, ao longo do processo, e de uma disponibilidade emocional autêntica por parte do plantonista, trazida por atitudes de aceitação positiva incondicional, empatia e congruência.

A esse respeito destaca Cury (1999, p.129):

... este serviço tem contribuído para nos aproximar da verdade sofrida que confere realismo ao suor e às lágrimas de nosso povo, mas paradoxalmente tem também aumentado nossa fé no processo dos relacionamentos interpessoais, pelos quais transita e é intensificada a possibilidade de recuperação da dignidade humana em sua mais nobre acepção.

Portanto, o benefício propiciado pelo Plantão Psicológico não utiliza como critério o grau de resolutibilidade do problema trazido pelo cliente, não sendo priorizado como foco do atendimento a demanda em si, considerada como algo objetivável e destituída dos significados que the são atribuídos, mas sim a pessoa, compreendida como um todo que se revela em suas formas pessoais de expressão, comportamentos, atitudes e emoções, visando conferir-Ihe autonomia, facilitando a reflexão na busca de trajetos possíveis de transpor as dificuldades que vivencia.

\section{Considerações Finais}

O estudo revelou um quadro heterogêneo quanto à distribuição da produção científica indexada em bases de dados sobre Plantão Psicológico no período de 1997 a 2009.
A delimitação imposta pelos critérios adotados pelas bases de dados exige qualidade nos trabalhos desenvolvidos e posteriormente indexados. De forma geral, esses trabalhos foram publicados em periódicos e divulgados principalmente no Banco de Teses Brasileiras da CAPES e apresentavam autor único, a maioria dos quais com vinculação à Universidade de São Paulo e à Pontifícia Universidade Católica de Campinas e de São Paulo, concentrando na Região Sudeste a produção sobre Plantão Psicológico.

A maioria dos trabalhos de pesquisa foram desenvolvidos nos anos de 2005 e 2006, sob a modalidade de dissertação, focalizando como população alvo adultos e utilizando como enfoque teórico dominante a Abordagem Centrada na Pessoa. Todavia, ressalva-se que a maior proporção de trabalhos indexados não corresponde necessariamente a maior produção na área, pois nem todos os editores submetem à indexação os trabalhos recebidos, seja por serem eles indeferidos em razão dos critérios adotados pela base de dados, seja porque não houve possibilidade ou iniciativa dos autores para fazê-lo. Portanto, apesar de apreciados por banca examinadora, tais trabalhos ficam restritos a poucos exemplares, dificultando sua divulgação.

A disponibilização do artigo na Internet, respeitando os direitos autorais, presta-se a promover a ciência, desafiando as dificuldades materiais e financeiras de acesso à bibliografia, principalmente da Região Norte do país.

As necessidades humanas e suas motivações podem ter um sentido emergencial para quem as vivencia e, nesse sentido, compreende-se o Plantão Psicológico como a clínica do acolhimento das urgências. Portanto, a assistência psicológica através dessa modalidade de atendimento contribui para que as pessoas lidem efetivamente com os impasses de suas vidas. Nesse sentido, evidencia-se a importância dessa modalidade de cuidados e do desenvolvimento de estudos na área.

\section{Referências}

Almeida, C. C. (2006). Plantão psicoeducativo paraeducadores em uma creche na periferia da cidade de São Paulo. Dissertação de mestrado não-publicada, Programa de Pós-Graduação em Educação, Pontifícia Universidade Católica de São Paulo. 
Almeida, F. M. (2005). Ser clínico como educador: uma leitura fenomenológica existencial de algumas temáticas na prática de profissionais de saúde e educação. Recuperado em agosto 31, 2009, disponível em http://www. teses.usp.br/

Araújo, A. T. S. (2002). Redes em psicologia clínica. Psikhe, 7 (2),32-37.

Aun, H. A. (2005). Trágico avesso do mundo: narrativas de uma prática psicológica numa instituição para adolescentes infratores. Dissertação de mestrado não-publicada, Programa de Pós-Graduação em Psicologia Escolar e do Desenvolvimento Humano, Universidade de São Paulo.

Braga, T. B. M. (2005). Práticas psicológicas em instituições e formação em psicologia: possibilidades de reflexões sobre o sentido da prática. Dissertação de mestrado não-publicada, Programa de Pós-Graduação em Psicologia Escolar e do Desenvolvimento Humano, Universidade de São Paulo.

Camargo, A. M. A. (2002). Desempenho de estagiários de clínica-escola em plantão psicológico. Dissertação de mestrado não-publicada, Programa de Pós-Graduação em Psicologia, Pontifícia Universidade Católica de Campinas.

Chalon, M. H. (2001). Contar histórias e expressar-se: aprendizagem significativa e plantão psicológico abrindo possibilidades para a clínica. Dissertação de mestrado não-publicada, Programa de Pós-Graduação em Psicologia, Universidade de São Paulo.

Chalom, M. H., Munhoz, C., Toledo, L. C. C., Ramalho, S. A., Souza, A. M. O., Moreira, A., el al. (1999). A Experiência de implantação de um serviço de plantão psicológico no projeto esporte-talento por alunos de graduação do IPUSP. In H. T. P. Morato (Org.), Aconselhamento psicológico centrado na pessoa: novos desafios (pp.175-182). São Paulo: Casa do Psicólogo.

Cipriano, F. L. (2005). Transmissão do conhecimento na especificidade da prática clínica em psicologia. Considerações sobre a perspectiva terapêutica em duas modalidades de atendimento clínico: o plantão psicológico e a psicoterapia breve. Tese de doutorado não-publicada, Programa de Pós-Graduação em Psicologia Social, Universidade de São Paulo.

Cury, V.E. (1999). Plantão Psicológico em clínica-escola. In M. C. Mahfoud (Org.), Plantão psicológico: novos horizontes (pp.115-123). São Paulo: Ed. Companhia Ilimitada.

Fernandes, D. L. (2005). Plantão psicológico em clínica escola: análise de vivências de plantonistas. Dissertação de mestrado não-publicada, Programa de Pós-Graduação em Psicologia, Pontifícia Universidade Católica de Campinas.

Ferreira, N. S., \& Yoshida, E. M. P. (2004). Produção Científica sobre psicoterapias breves no Brasil e demais países latino-americanos (1990-2000). Estudos de Psicologia (Natal), 3 (3), 523-531.

Ferreira, R. S. (2006). Possíveis implicações da experiência com plantão psicológico para a ação do psicólogo clínico. Dissertação de mestrado não-publicada, Programa de Pós-Graduação de Psicologia Clínica, Pontifícia Universidade Católica de Pernambuco, Recife.

Furigo, R. C.P. (2006). Cuidando de crise emocionais no plantão psicológico referendado na escola junguiana. Tese de doutorado não-publicada, Programa de Pós-Graduação em Psicologia, Pontifícia Universidade Católica de Campinas.

Guedes, M. A. (2006). Intervenções psicossociais no sistema carcerário feminino. Psicologia Ciência e Profissão, 26 (4), p.558-569. Recuperado em agosto 31, 2009, disponível em <http://pepsic.bvs-psi.org.br/scielo.php>. doi: S14 14-98932006000400004.

Kovács, M. J., Kobayashi, C., Santos, A. B. B., \& Avancini, D. C. F. (2001). Implantação de um serviço de plantão psicológico numa unidade de cuidados paliativos. Boletim de Psicologia, 51, 1-22.

Mahfoud, M. (Org.). (1999). Plantão psicológico: novos horizontes. São Paulo: Companhia llimitada.

Melo, F. F. S. (2004). Plantão psicoeducativo:espaço de reflexão e mudança oferecido às famílias de uma comunidade de baixa renda. Dissertação de mestrado não-publicada, Programa de Pós-Graduação em Educação, Pontifícia Universidade Católica de São Paulo.

Messias, T.S.C. (2002). Plantão psicológico como possibilidade de facilitação à tendência atualizante: um estudo clínico. Dissertação de mestrado não-publicada, Programa de Pós-Graduação em Psicologia, Pontifícia Universidade Católica de Campinas.

Moreira, E. N. (2002). Plantão psicológico em ambulatório de saúde mental: um estudo fenomenológico. Dissertação de mestrado não-publicada, Programa de Pós-Graduação em Psicologia, Universidade Católica de Campinas.

Mosqueira, S. M. (2008). À procura de sentido de atenção psicológica com adolescentes em privação de liberdade. Recuperado em setembro 13, 2009, disponível em $<$ http://servicos.capes.gov.br/capesdw/resumo.html? idtese>. doi: 20082833002010038P7.

Mozena, H. (2009). Plantão psicológico:estudo fenomenológico em um Serviço de Assistência Judiciária. Recuperado em agosto 22, 2009, disponível em <http://www.biblioteca digital.puc-campinas.edu.br>.

Oliveira, M. M. (2006). Clínica, experiência e sentido: narrativas de plantonistas. Recuperado em agosto 21, 2009, disponível em <http://servicos.capes.gov.br/ capesdw/ resumo.html?idtes>. doi: 20062833002010038 P7.

Oliveira, R. G. (2005). Uma experiência de plantão psicológico à polícia militar do Estado de São Paulo: reflexões sobre sofrimento e demanda. Dissertação de mestrado não-publicada, Faculdade de Psicologia, Universidade de São Paulo.

Palmiere, T. H. (2005). Plantão psicológico em hospital geral: um estudo fenomenológico. Dissertação de mestrado não-publicada, Programa de Pós-Graduação em Psicologia, Pontifícia Universidade Católica de Campinas.

Paparelli, R. B. (2005). Psicólogos em formação: vivências e demandas em plantão psicológico. Dissertação de mestrado não-publicada, Programa de Pós-Graduação em Ciências, Coordenadoria Controle de Doenças da Secretaria Estadual da Saúde de São Paulo.

Paparelli, R. B., \& Nogueira-Martins, M. C. F. (2007). Psicólogos em formação: vivências e demandas em plantão psicológico. Psicologia Ciência e Profissão, 27 (1), 64-79. 
Perches, T. H. P. (2009). Plantão psicológico: o processo de mudança psicológica sob a perspectiva da psicologia humanista. Recuperado em agosto 20, 2009, disponível em <http://www.bibliotecadigital.puc-campinas.edu. $b r>$.

Pereira, P. C. (1999). A Entrevista única: uma nova modalidade de atendimento na psicologia clínica. Dissertação de mestrado não-publicada, Programa de Pós-Graduação em Psicologia, Pontifícia Universidade Católica de Campinas.

Rocha, M.C. (2006) Juventude: apostando no presente. Imaginário, 12 (12), 205-223.

Rosemberg, R.L. (Org.) (1987). Aconselhamento psicológico centrado na pessoa (Temas Básicos de Psicologia, vol. 21). São Paulo: EPU.

Schmidt, M.L.S. (2004). Plantão Psicológico, Universidade Pública e Política de Saúde Mental. Estudos de Psicologia (Campinas), 21 (3), 173-192. doi: 10.1590/S0103-166X2 0044000300003

Talmom, M. (1990). Single session therapy. San Francisco, CA: Josseu-Bass.

Tassinari, M. A. (1999). Plantão psicológico centrado na pessoa no contexto escolar e a promoção da saúde. Dissertação de Mestrado não-publicada, Programa de Pós-Graduação em Psicologia, Universidade Federal do Rio de Janeiro.

Tassinari, M. A. (2003). A clínica da urgência psicológica: contribuições daabordagem centrada na pessoa e da teoria do caos. Tese de doutorado não-publicada, Programa de Pós-Graduação em Psicologia, Universidade Federal do Rio de Janeiro.

Vendruscolo, J. (2006). A criança curada de cânceringressando no ambulatório de curados: um momento de passagem. Recuperado em agosto 23, 2009, disponível em <http:// servicos.capes.gov.br/capesdw/resumo.html>.doi: 2006 4433002029030P1.

Yamamoto, O. H., LoBianco, A. C., Hutz, C. S., Bueno, J. L. O, Guedes, M. C., Koller, S. H., et al. (2002). Avaliação de periódicos científicos brasileiros da área da psicologia. Ciência da Informação, 31 (2), 163-177.

Yamamoto, O. H., Souza, C. C.,\& Yamamoto, M. E. (1999). A produção científica na Psicologia: uma análise dos periódicos brasileiros no período de 1990-1997. Psicologia: Reflexão e Crítica, 12 (2), 549-565.

Yehia, G. Y. (2004) Interlocuções entre o plantão psicológico e o psicodiagnóstico colaborativo Estudo de Psicologia (Campinas), 21 (1), 65-72. doi: 10.1590/S0103-166X200 4000100006.

Zanoni, M. R. L. (2008). Plantão psicológico em um serviço universitário de psicologia: a experiência de aprimorandas. Recuperado em agosto 26, 2009, disponível em <http:// www.scielo.br>.

Recebido em: 8/1/2009

Versão final reapresentada em: 12/4/2010

Aprovado em: 4/2/2011 
